\title{
Erratum to: 2-D Duffing Oscillator: Elliptic Functions from a Dynamical Systems Point of View
}

\author{
Francisco Javier Molero • Martín Lara • \\ Sebastián Ferrer • Francisco Céspedes
}

Published online: 6 March 2013

(C) Springer Basel 2013

\section{Erratum to: Qual Theory Dyn Syst DOI 10.1007/s12346-012-0081-1}

In the original publication of the article, Figs. 3 and 5 are incorrect. The correct versions of Figs. 3 and 5 are given below:

The online version of the original article can be found under doi:10.1007/s12346-012-0081-1.

\section{F. J. Molero $(\varangle) \cdot$ M. Lara $\cdot$ S. Ferrer $\cdot$ F. Céspedes}

Departamento de Matemática Aplicada, Universidad de Murcia, Campus de Espinardo, 30071 Espinardo, Murcia, Spain

e-mail: franciscojavier.molero@um.es

\section{Lara}

e-mail:mlara0@gmail.com

S. Ferrer

e-mail: sferrer@um.es

F. Céspedes

e-mail: franciscojuan.cespedes@um.es 


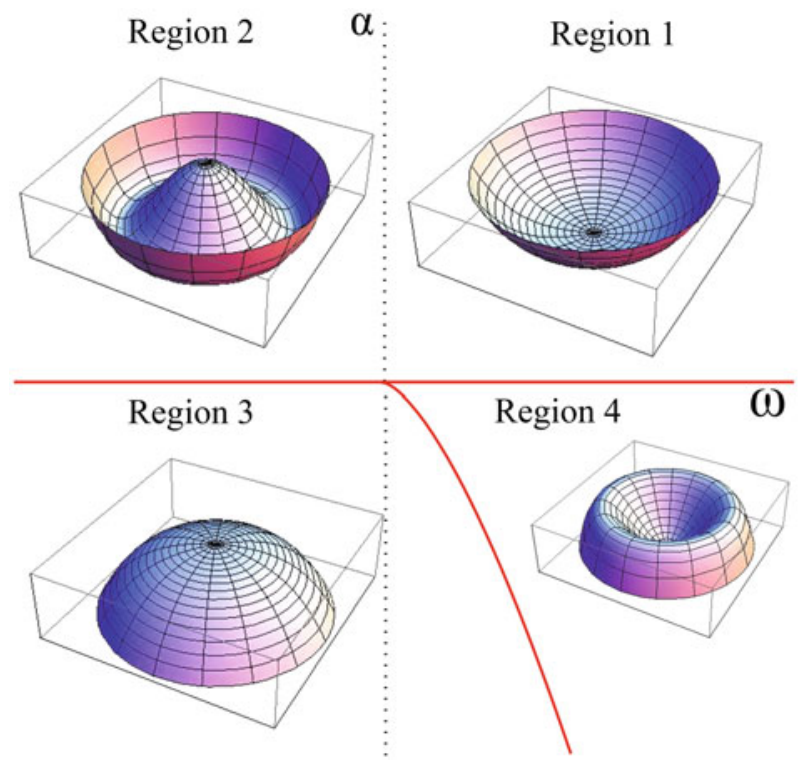

Fig. 3 Different types of 3D potentials represented from (29) over the parameter plane. Regions with bounded motions can be appreciated. All figures are "revolution plots" where $x^{2}+y^{2} \equiv r^{2}$

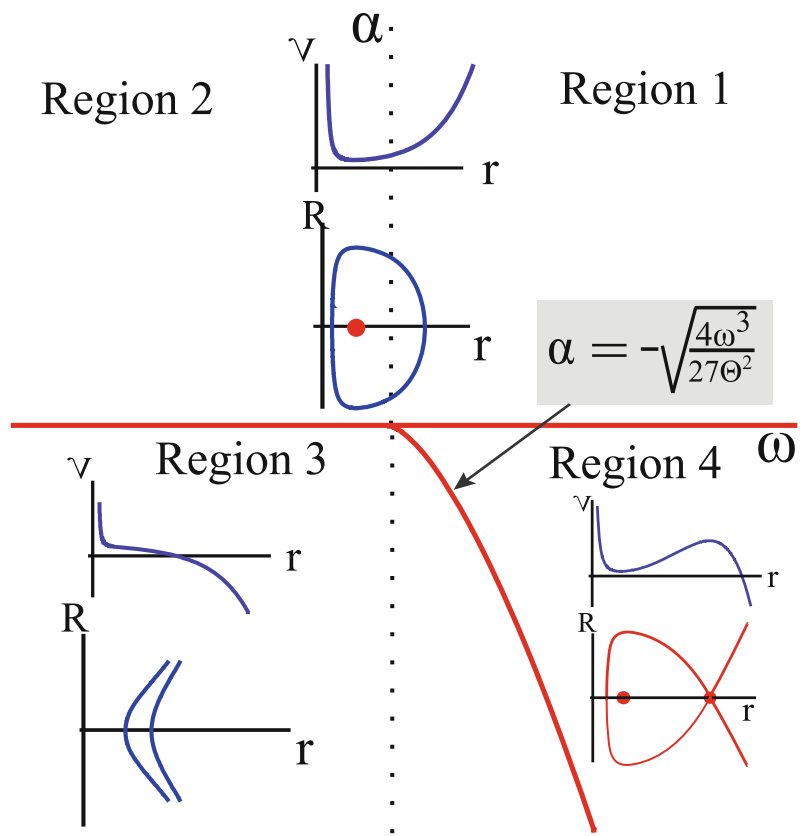

Fig. 5 Effective potential and reduced radial flows. The value of the integral is $G=0.1$. Details of the region 4 are given in Fig. 7 